\title{
An Attempt to Enhance Daylighting in Educational Buildings Using Interactive Facades
}

\author{
Mohamed M.Elfakharany ${ }^{1}$, M.A.M.Hanafi' ${ }^{2}$, Mona M. Abdelhamid ${ }^{3}$
}

\begin{abstract}
Many educational buildings suffer from poor environmental conditions. As, they lack of appropriate daylighting performance as well as an uncomfortable thermal environment. The reason for this condition is usually considered due to a lack of an overall design solution. It is very important to take into account the variation of daylighting and thermal conditions throughout different periods of the year. Responsive architecture offers a solution depending on interactive façade systems that can operate upon the user's preference or independently using sensors manipulating the interactive system. The aspects upon which the façade can perform automatically are various, such as solar radiation, illumination and thermal comfort. The optimum solution could be a balanced switching between the natural daylighting and the electrical lighting for the spaces. The integration of the two type of illumination will provide an energy efficient building that could create a comfortable space satisfying the users of the space by maintaining the required illumination levels for the various functions held in the spaces. By benefiting from a renewable source of light energy, this will help in minimizing the energy consumption as well as the carbon foot print for the building in order to enhance educational building energy performance.
\end{abstract}

Keywords: natural lighting, responsive facades, educational building, energy conservation, digital applications

\section{Introduction}

With the great digital revolution in the world of architecture, nowadays, the design of interactive façade for educational building had become the optimum solution for energy efficiency and healthy environment. Focusing on the important role of responsive building skin which has the ability to respond intelligently to the outdoor illumination conditions and the internal performance needs, the quality of daylighting within the interior of educational spaces could be automatically adjusted in order to achieve healthy and sustainable educational environment. The challenge for responsive building skin is to find the balance between cooling and lighting use, while providing thermal comfort, glaring and occupant wellbeing.

This paper will discuss the implementation possibilities for responsive façade units in educational building while integrating computer-generated models for simulation and evaluation, using parametric and algorithmic computation. A case study of an architecture studio at pharos university in Alexandria will be examined as an educational space where student spend long durations practicing various educational activities, that requires several lighting requirements.

$\mid{ }^{1} \mathrm{BSC}, \mathrm{Ph} . \mathrm{D}$ Lecturer of architecture, Faculty of Engineering, Pharos University in Alexandria, Alexandria, Egypt

${ }^{2} \mathrm{BSc}$, Ph.D, professor of Architecture, Faculty of Architecture:Design \&the built Environment, Beirut Arab University, Lebanon.

| 3 BSC, Ph.D, Lecturer of architecture, Faculty of Engineering, Pharos University in Alexandria, Alexandria, Egypt. 


\subsection{The Scope of this Paper}

This paper focuses on highlighting the importance of providing energy efficiency in educational buildings by maximizing the dependency on natural daylighting for educational spaces. When aiming to achieve green and sustainable building design, it is very important to consider the largest overall environmental impacts resulting from annual energy use associated with providing visual comfort in a building.

\subsection{Aim of this Paper}

This paper aims to draw attention to the importance of integrating digital solution for buildings facades of educational buildings in order to maximize daylighting during the working hours of the day. This consequently, will help in reducing the carbon footprint of the building.

\section{Natural Lighting for Educational Buildings}

The main purpose of using natural lighting is to benefit from the unique quality of daylighting as well as to link the interior space with the external environment. The educational spaces designs should assume that daylight would be the essential means of lighting when it is available, unless there are other purposes of spaces such as in a video room or other special activities. However, in some cases windows can became a source of discomfort and can cause eye fatigue when there is a particularly bright sky or when the penetration of direct sunlight disrupts the activities within the space.( Loe D., Rowlands E. and Mansfield K., 1999)

Thus, considering the design of responsive windows and facades can be a complex and important part of building design which will need to be carefully designed in order to achieve maximum benefit and pleasure together with minimum dissatisfaction.
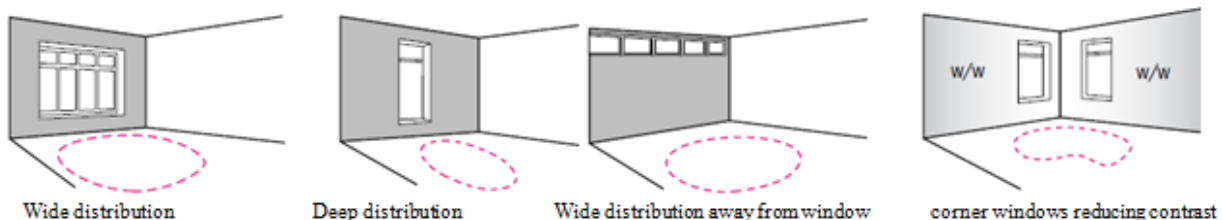

Figure 1: Shows how can the shape, size and position of windows affects the way in which daylight is distributed within the interior space. Source: Loe D., Rowlands E. and Mansfield K., 1999

\section{Reasons for Replacing Conventional Window Facades with more Intelligent Interactive Building Facades}

A conventional static glass windows and skin will not be able to achieve the optimal performance needed during different periods and months of the year. The manually controlled blinds by occupants will not fundamentally adjacent the performance picture of the building. On the other hand, the interactive façade usually includes systems that enhance the performance of the glass and adjust solar gain, daylighting, heat loss and ventilation by responding to the outdoor conditions changes. It also allows for the occupants of the building to adjust their indoor comfort parameters 
using more precise computerized sensors. That is why, dynamic control of building skin became recently very important approach for daylighting management in buildings designs which aim at achieving the maximum energy efficient control. While, energy and visual comfort criteria are likely to be strongly linked to each other, human preferences for temperature, light levels, view, etc are considered to be consistent for a single individual but more variable between different individuals. In order to meet these different human need for different group users at different period of time, the traditional building envelope has to be replaced or supplemented with a more active skin. Thus, it is highly needed to use an intelligently controlled, dynamic envelope in order to enhance the human comfort while using the building at different period of time. Therefore, the interactive façade concept can be seen as an effective solution both to actively manage the changing "incident" climatic conditions and occupant interior needs based on both changing tasks and variable preferences. This starts with better utilization of energy flows associated with daylighting and useful solar gain it can also include building integrated photovoltaic systems, BIPV for energy efficient artificial lighting control during the night. There is no doubt that these new functions potentially add complexity and cost to the envelope both in the hardware design and during the operation of the building. Basically, these systems will only be used in a wide range if their overall lifecycle benefits, measurable and realized, exceed their costs. (Selkowitz, S., Ø A., \& E. S. 2003)

\section{Daylight Design Measurements}

The design guidance used for daylighting measurements used is the daylight factor which is according to lighting design for school book, 1999 is: "the percentage of the horizontal diffuse illuminance outdoors from an unobstructed sky hemisphere which is received at a point indoors: there are three components [the component received directly from the sky (Sky Component), the component received by reflection from external surfaces (Externally Reflected Component) and the component received by reflection from internal surfaces (Internally Reflected Component)."

However Natural lighting is very variable, as the Daylight Factor will vary within different spaces according to a number of parameters, which include:

- The size and disposition of the glazing

- The dimensions of the space

- The reflectance of the interior surfaces

- The degree of external obstruction

- The position of the sun during the day
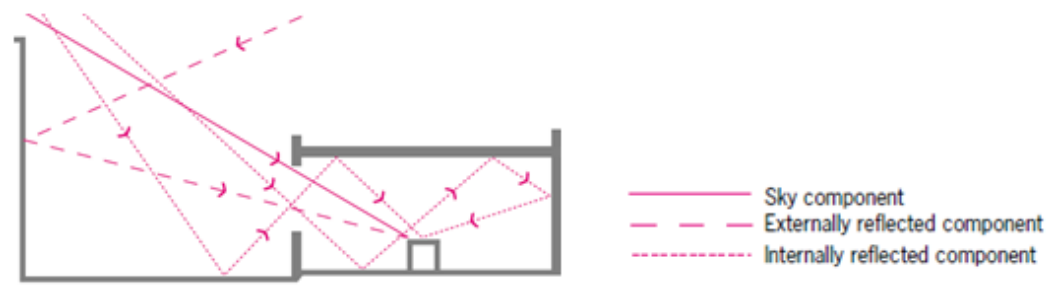

Figure 2: Shows different parameters that affect daylight factor, Source:( Loe D., Rowlands E. and Mansfield K., 1999) 
If the average of daylighting factor within the interior space is equal or exceed the percentage of $5 \%$ then the interior can be considered to day lit space and will not normally require electric lighting. Whereas, interior spaces where the Average Daylight Factor is below 2\% will need additional use of electric lighting. Interior spaces where the Average Daylight Factor is between $2 \%$ and $5 \%$ as well will need a mix of electric lighting between October and March and natural lighting for other months of the year.( Loe D., Rowlands E. and Mansfield K., 1999)

According to Loe D., Rowlands E. and Mansfield K., 1999, in the book (Lighting Design for Schools) the Average daylight factor (DF) can be estimated from the following formula, which can be applied for vertical glazing and to some roof-lights.

$\boldsymbol{T}=$ diffuse transmittance of glazing material including effects of dirt.

(Clean clear single and double glazing have a typical transmittance value of 0.80 and 0.65 respectively. The dirt on glass is a factor that has to be also considered when calculating the $T$ value. The suitable correction factors are given in table 1)

$\boldsymbol{W}=$ net glazed area of window $(\mathrm{m} 2)$

$\ldots=$ angle in degrees subtended, in the vertical plane normal to the window, by sky visible from the center of the window (it is shown in the following figure)

$\boldsymbol{A}=$ total area of interior surfaces including windows ( $\mathrm{m} 2)$

$\boldsymbol{R}=$ area-weighted average reflectance of interior surfaces, including windows (table 2)

Table 1: Correction factors to transmittance values for dirt on glass.

Correction factors for dirt on glass $(T)$

\begin{tabular}{|c|c|c|c|}
\hline Type of loaction & Vertical window & Sloping window & Horizontal window \\
\hline Clean & 0.9 & 0.8 & 0.7 \\
\hline Industrial & 0.7 & 0.6 & 0.5 \\
\hline Very dirty & 0.6 & 0.5 & 0.4 \\
\hline
\end{tabular}

Source:( Loe D., Rowlands E. and Mansfield K., 1999)

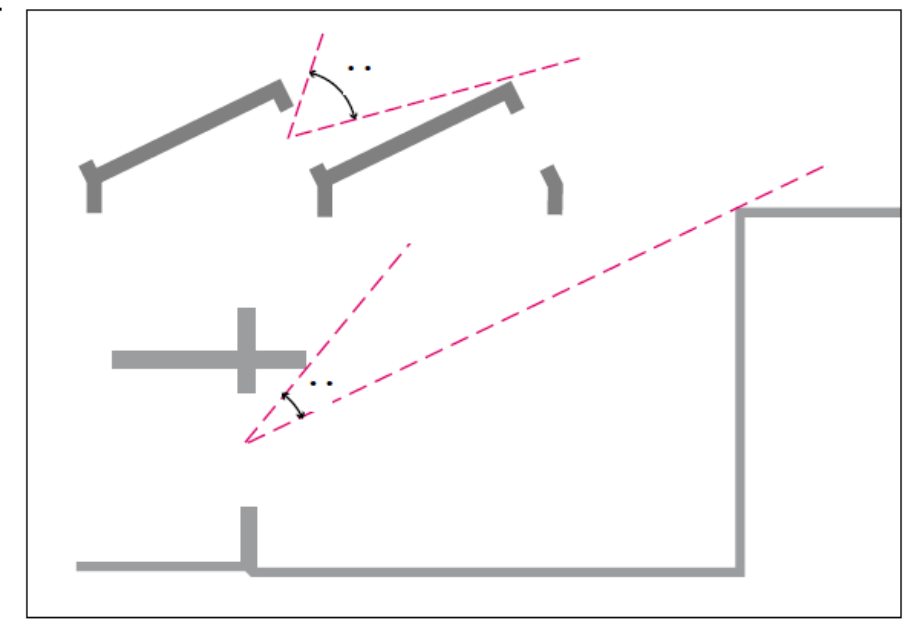

Figure 3: Angle ** which defines visible sky from center of window/ roof light,

Source:( Loe D., Rowlands E. and Mansfield K., 1999) 
Table 2: Approximate reflectance values for various surface finishes

\begin{tabular}{|c|c|c|c|}
\hline Paint colors & Reflectance & Internal materials & Reflectance \\
\hline White & 0.85 & White paper & 0.8 \\
\hline Pale cream & 0.8 & Carpet & $0.45-0.1$ \\
\hline Light grey & 0.7 & Brickwork & $0.3-0.2$ \\
\hline Mid-grey & 0.45 & Quarry tiles & 0.1 \\
\hline Dark grey & 0.15 & Window glass & 0.1 \\
\hline Dark brown & 0.1 & \multicolumn{2}{|}{} \\
\hline Black & 0.05 &
\end{tabular}

Source:( Loe D., Rowlands E. and Mansfield K., 1999)

All educational buildings have several spaces, where many of them can be used for a number of different activities. Thus, it is necessary for the architect designer to identify the particular activities that will take place in each of the spaces, in order to achieve appropriate lighting design. The research concentrates mainly on the amount and quality of daylighting needed for the 'general teaching spaces'.

The main purpose of using natural daylighting are mainly linked with:

a- function - to enable tasks to be achieved accurately and comfortably and to create good movement through the building

b- amenity - to light the interior of the building in order to provide a pleasant and stimulating environment.

Loe D., Rowlands E. and Mansfield K., 1999 have assumed that the illuminance of the interior space provided by the daylight can be calculated from the following equation.

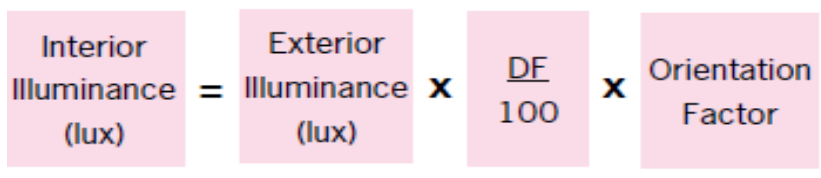

The Window Orientation Factor should be considered because even with overcast skies, there is a huge variation in luminance according to window located in different orientation of the building, with the southern sky having the greatest effect. Average values of Orientation Factor are given in the following table (form 09.00 to 17.00 during the day):

Table 3: Window orientation factors for calculation of interior illuminance. Source:( Loe D., Rowlands E. and Mansfield K., 1999)

\begin{tabular}{|c|c|}
\hline Orientation of the window & Orientation factor \\
\hline North & 0.97 \\
\hline East & 1.15 \\
\hline South & 1.55 \\
\hline West & 1.21 \\
\hline
\end{tabular}

Providing good natural lighting from large glazing surfaces can be considerable as energy savings solution. However, if it is not properly considered early in the design process it can causes many problems such as heat loss in winter and heat gain in summer as well as 
causing something visual discomfort for users of the space. (Loe D., Rowlands E. and Mansfield K., 1999)

Designing interactive window facades that can change its size, orientation and position by responding to the variation of the exterior illuminance can be a good solution for these problems. Another solution may be achieved by providing responsive blinds and sun-shading devices. These will increase the initial building cost but they have the potential of considerably reducing running costs, and a balanced view needs to be taken. Unclean window glazing will also cause a gradual reduction of the amount of daylight penetrating into the interior space that is why providing self-cleaning glass for windows will also decrease the effect of dirt glass on the amount of illuminance.

According to the CIBSE Code for Interior Lighting, 1994, 'Section 2.6.4.4 Public and education buildings' the standard illuminance for specific interiors educational spaces and activities is shown in the next table.

Table 4: Illuminance Index for schools and educational spaces. Source:( Loe D., Rowlands E. and Mansfield K., 1999)

\begin{tabular}{|l|l|}
\hline Type of the space & $\begin{array}{l}\text { Standard maintained } \\
\text { illumination (lux) }\end{array}$ \\
\hline Typical teaching spaces & 300 lux \\
\hline $\begin{array}{l}\text { Teaching spaces with close and detailed work (such as art } \\
\text { rooms and architecture studios as well as craft rooms) }\end{array}$ & 500 lux \\
\hline
\end{tabular}

\section{Visual Quality of Daylighting in Educational Buildings}

The best educational environments usually give a general feeling of pleasantness, which in turn positively influence students' ability on concentrating into their classes as well as increasing general productivity. There can be no doubt that both natural and electrical lighting plays a significant if not the main role in enhancing human comfort within the educational space. Natural lighting during daylight hours should always be the major source, supplemented when it fades by electric light that will take over during hours of darkness. However, there are usually changing value for daylighting throughout the teaching day linked with the changing of solar angels during the day. Lack of attention to detailed window design can create poor visual conditions as under glazing can make dark and gloomy interior spaces, whereas, over glazing can create glare as well as excessive solar gain in summer and excessive heat loss in winter accompanied with pupil discomfort. Therefore, applying responsive windows on the educational building facades can represent an effective solution in order to overcome those problems. (Loe D., Rowlands E. and Mansfield K., 1999)

Parametric simulation computer application provide advantage of calculating and testing the architecture design that can achieve better daylighting efficiency during different period of the day by calculating the interior illumination of the educational space regarding all the discussed factors (daylighting factor (DF); orientation factor and the exterior illumination factor). Advanced computer software such as diva for rhino software can provide a realistic simulation environment that can help architect in choosing the most efficient design solution achieving maximum daylighting efficiency for 
educational spaces. A simulation and analysis in diva for rhino software has been applied on an architectural studio at Pharos University in Alexandria, as an example for a main educational space, where students spent most of the day in various activities.
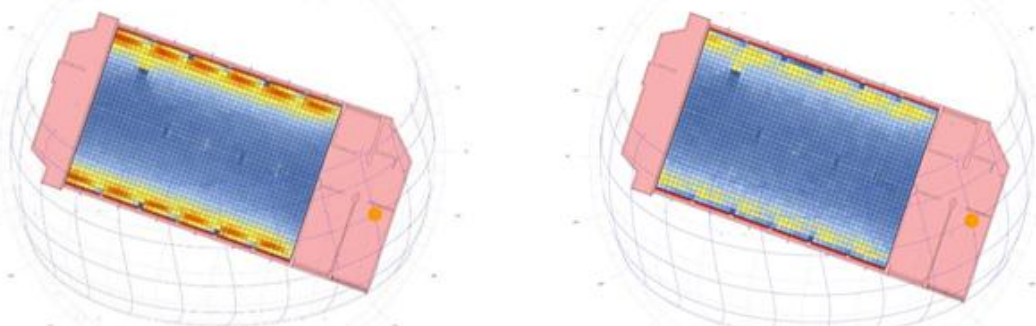

Figure 4 : left, space without automated interactive units, right: same space at the same time of the day, but with interactive units operating. (source: by the author)

This example has proved that the usage of responsive interactive units on the façade has contributed dramatically in achieving a better visual quality through minimizing high intensity of illumination and glare caused by natural daylighting.

\section{Using Computer Aided Models for Daylighting Calculation}

Advanced computer aided models are used recently in order to enhance natural daylighting calculation through different time of the day. There have been an analysis made by Stephen Selkowitz, Øyvind Aschehoug, Eleanor S., they mixed together some trends that characterize recent market directions concerning responsive skin with other future performance needs and objectives for R\&D group (researches and development relating to sustainable design of buildings and the development of façade components and systems to achieve natural daylighting using computer aided models) on advanced facades in the coming years. In this analysis, they summarized these goals and trends into 6 main issues that are needed to achieve better daylighting design calculation. (Selkowitz, S., ØA., \& E. S. 2003)

\begin{tabular}{|c|c|c|}
\hline \multicolumn{3}{|c|}{$\begin{array}{l}\text { Issues needed to Improve daylighting } \\
\text { calculation using parametric simulation }\end{array}$} \\
\hline $\begin{array}{l}\text { Enhancing com- } \\
\text { puter simulation }\end{array}$ & $\begin{array}{l}\text { Using of physical } \\
\text { models }\end{array}$ & $\begin{array}{c}\text { Using advanced } \\
\text { glazing technolo- } \\
\text { gies }\end{array}$ \\
\hline $\begin{array}{l}\text { Integrating the respn- } \\
\text { sive facades in an } \\
\text { early design stage }\end{array}$ & $\begin{array}{l}\text { Using advanced } \\
\text { sensors and con- } \\
\text { trol technologies }\end{array}$ & $\begin{array}{l}\text { Relating the build- } \\
\text { ing to the infra- } \\
\text { structure }\end{array}$ \\
\hline
\end{tabular}

Figure 5 : Issues needed to improve daylighting calculation using parametric simulation, source: (Selkowitz, S., Ø A., \& E. S. 2003) and modified by the researcher

\subsection{Enhancing Computer Simulation}

Simple computer simulation can be used in the design process of a nonresponsive façade to calculate the daylighting during the peak period of the day. On the 
other hand, advanced design tools of computer programs are needed to design more intelligent responsive facades, as it depends on the dynamic nature of the façade, in response for the fluctuating natural conditions. Simulation tools seek more abilities in the field of energy simulation, by applying different operational modes and different materials that are applied on a computer generated model. These computer software applications can provide calculations in an accurate form, while it still need more modification in the field of optically complex glazing and shading systems. The computer application should also be used in post occupancy building management and operation to provide accurate measures for the systems. (Lee et al. 2002).

\subsection{Using of Physical Models}

Physical model is needed to enhance efficiency and applicability of responsive systems. It is used also to properly introduce these advanced systems to a broader range of clients and land owners, as well as enabling the architects and engineers working in that field to get the full experience and the experimentation of such technology. (Selkowity, S., Ø A., \& E. S. 2003)

\subsection{Integrating the Responsive Facades in Early Design Stages}

When aiming for an advanced architectural construction adopting responsive techniques, an important phase is the phase of computer modeling and simulation. Which will add to the cost of the design stage, this preconstruction examination and testing saves a lot of money in the post construction stage. A good example is the use of special type of glazing with automatic controlled shading that can allow efficient heat transfer without any losses or extra gains. When the landowner understands, a good result could be reached while cooperating with the designer, by appreciating the early design process in contributing in the post construction and operational costs. (McConahey et al. 2002). The benefits will reflect on the energy consumption bill as well as minimizing the carbon emission, and proving the benefiting on the long term. (Selkowity, S., Ø A., \& E. S. 2003)
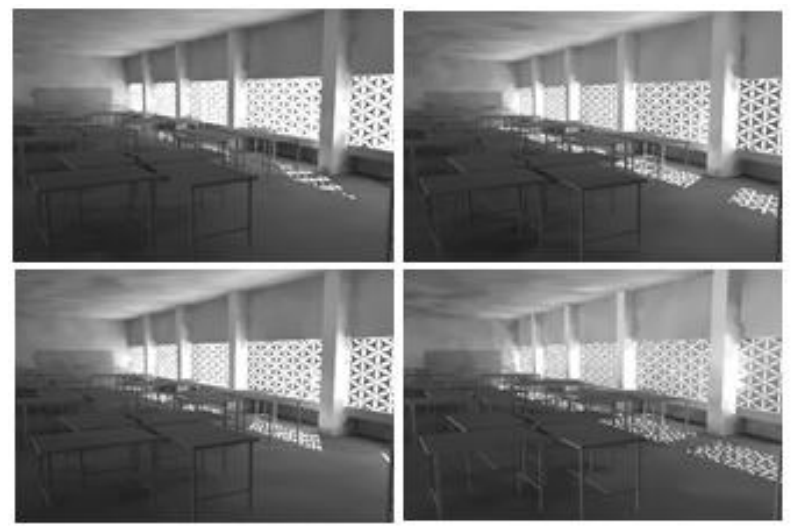

Figure. 6 Examples of shading systems simulation for an architecture studio, at Pharos University in Alexandria (20 NOV-daylighting), (source: by the author) 


\subsection{Using Advanced Sensors and Control Technologies}

An automated system for controlling the windows operation is needed generally in public building for the achievement of better building performance. These systems are manipulated through advanced communication technologies that can calculate more accurately the comfortable natural illumination of the space regarding multiple factors as discussed before. These technologies will also control the responsive units such as motorized shades or electrochromic glazing during different time of the day (Rubinstein et al. 2000). Beside the achievements that result from using the responsive systems, an advantage of recording the errors and some problem solving techniques could be introduced to the systems.

\subsection{Using Advanced Glazing Technology}

The main challenge of the system is to provide a well day lit space, while still avoiding extra solar radiation or glare effect. Using advanced glazing materials that control the amount of the daylight penetrating to the interior space can enhance the performance of the responsive facades. The advanced glass surface can stops or permit a percent or totally permit the daylight by the rearrangement of the molecules of the material layers according to the electric current passing through the material. (Selkowits, S., Ø A., \&E. S. 2003)
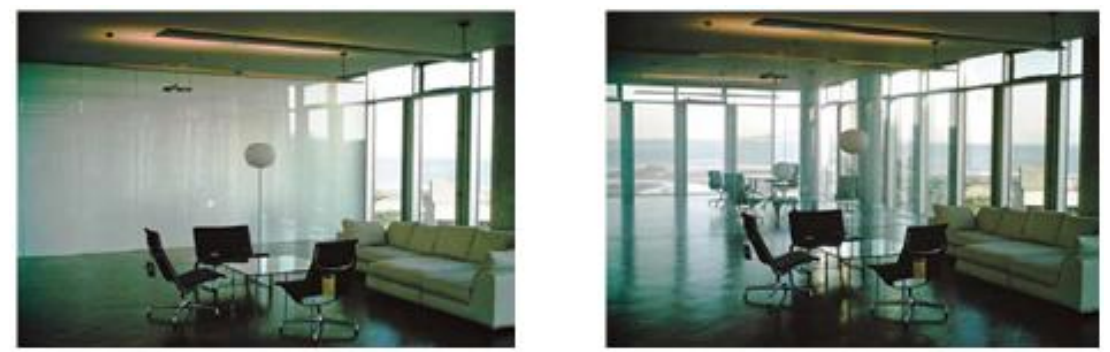

Figure 7: switchable glass enabling visual contact and natural daylighting (source: Fox, M., \& Kemp, M. (2009)

\subsection{Relating the Building Infrastructure to the Local or Regional Electric Grid}

Electrical energy consumption is considered one of the biggest environmental impacts of building operations. In order to consider a building as a positive environmental contributor, the infrastructure of the building should be connected with the regional electrical grid. Governments should encourage building owners and enterprises to adopt the technologies that participate lower energy consumption to minimize the building carbon foot print (Lee et al. 2002).

\section{Conclusion}

The possibilities of applying responsive systems in educational buildings are endless as technology advances, however architects, designers and decision makers must take advantage of that technology and knowledge to aid in achieving more sustainable architecture design solutions. The applicability of these advanced solutions cannot be achieved unless the society consider important to raise the awareness of clients and 
owners as well as architects and designer about the huge role that responsive systems play in minimizing the energy consumption, through using the sun position as a parameter that contribute in minimizing the illuminance value in educational spaces. Responsive architecture design is not concerned only by the reduction of the harmful impact of solar radiation in the space and the glare problems associated by the natural daylighting, but also seek to create a livable environment by mimicking the nature in adapting to the external environment and achieve comfort for the building its self, represented in the users, thus linking the architecture to the nature, and have the ability to reengage the user to the natural environment as well as the contribution in minimizing the energy consumption.

According to the studied benefit of designing interactive facades for educational buildings, this method can be used in order to take full advantage of the available daylight which will require an automatic daylight linked control system.

\section{References}

Fox, M., \& Kemp, M. (2009). Interactive architecture. New York, NY: Princeton Architectural.

Lee, E.S., et.al. 2002. "Active Load Management with Advanced Window Wall Systems: Research and Industry Perspectives." Proc. ACEEE 2002 Summer Study Asilomar, CA. LBNL-50855.

Loe D., Rowlands E. and Mansfield K., 1999, "Lighting Design for Schools" Published by Crown, London, UK

McConahey, E., P. Haves, and T. Christ. 2002. "The Integration of Engineering and Architecture: a Perspective on Natural Ventilation for the San Francisco FederalBuilding," Proc. 2002 ACEEE Summer, Asilomar, CA, LBNL \# 51134.

Rubinstein, F, S Johnson and P Pettler. 2000. "An Integrated Building Environmental Communications System (IBECS): It's Not Your Father's Network,” Proc. 2000 ACEEE Summer Study, Asilomar, CA.

Selkowitz, S., Ø A., \& E. S. (2003). Advanced Interactive Facades - Critical Elements for Future Green Buildings?. GreenBuild, the annual USGBC International Conference and Expo. 